\title{
Thermal-Structural Analysis of PICA Tiles for Solar Tower Test
}

\author{
Parul Agrawal ${ }^{*}$ \\ ELORET Corporation, Sunnyvale, CA 94087 \\ Daniel M. Empey ${ }^{\dagger}$ \\ Sierra Lobo Inc. \\ Thomas H. Squire \\ NASA Ames Research Center, Moffett Field, CA 94035-1000
}

\begin{abstract}
Thermal protection materials used in spacecraft heatshields are subjected to severe thermal and mechanical loading environments during re-entry into earth atmosphere. In order to investigate the reliability of PICA tiles in the presence of high thermal gradients as well as mechanical loads, the authors designed and conducted solar-tower tests. This paper presents the design and analysis work for this tests series. Coupled non-linear thermalmechanical finite element analyses was conducted to estimate in-depth temperature distribution and stress contours for various cases. The first set of analyses performed on isolated PICA tile showed that stresses generated during the tests were below the PICA allowable limit and should not lead to any catastrophic failure during the test. The tests results were consistent with analytical predictions. The temperature distribution and magnitude of the measured strains were also consistent with predicted values. The second test series is designed to test the arrayed PICA tiles with various gap-filler materials. A nonlinear contact method is used to model the complex geometry with various tiles. The analyses for these coupons predict the stress contours in PICA and inside gap fillers. Suitable mechanical loads for this architecture will be predicted, which can be applied during the test to exceed the allowable limits and demonstrate failure modes. Thermocouple and straingauge data obtained from the solar tower tests will be used for subsequent analyses and validation of FEM models.
\end{abstract}

\section{Introduction}

Phenolic Impregnated Carbon Ablator (PICA) ${ }^{1}$ was developed by scientists at Thermal Protection Materials and Systems Branch at NASA Ames Research Center. As the name suggests, it is made by impregnation of phenolic resin inside a carbon fiber preform. It is a lightweight low-density material with very high porosity. In the presence of high heat flux, it pyrolyzes and forms a char layer. It was selected as the heatshield material on the Stardust sample-return capsule. ${ }^{2}$ PICA has also been selected as one of two primary candidate Thermal Protection System (TPS) materials for the Orion Crew Module ${ }^{3}$ and the heatshield material for Mars Science Laboratory (MSL). ${ }^{4}$

Many different tests are being performed by the Orion TPS Advanced Development Project team to characterize the mechanical and thermal properties of virgin and charred PICA. ${ }^{5}$ The heatshield on the Stardust re-entry capsule was made from a single piece of PICA formed to the final shape. However, both MSL and Orion heatshields will be significantly larger; hence the architecture uses many blocks of PICA (shaped like tiles) bonded together with the

\footnotetext{
* Senior Research Scientist, NASA Ames Research Center, Thermal Protection Materials and Systems Branch, MS 234-1, Moffett Field, CA 94035, AIAA Member

${ }^{\dagger}$ Senior Mechanical Engineer, NASA Ames Research Center, Thermo-Physics Facilities Branch, MS 230, Moffett Field, CA 94035

* Aerospace Engineer, NASA Ames Research Center, Thermal Protection Materials and Systems Branch, MS 234-1, Moffett Field, CA 94035, AIAA Member
} 
help of gap-filler material. Extensive thermal-mechanical stress analysis is being conducted at various steps of lunar trajectory for the Orion crew module to investigate the performance of PICA tiles with various gap-filler options and to arrive at optimum tile size. The entry of the crew module into earth atmosphere is critical, introducing very large thermal gradients to the top layer of the heatshield. Figure 1 shows a snapshot of temperature distribution along thickness. The stress analyses for re-entry conditions shows the presence of very high in-plane compressive stresses caused by these high temperature gradients. Sometimes these stresses exceeded the allowable stresses for PICA. One of the concerns raised by the project management was whether these stresses would lead to initiation of cracks or damage in the heatshield or, in the worst case, could lead to a catastrophic failure.

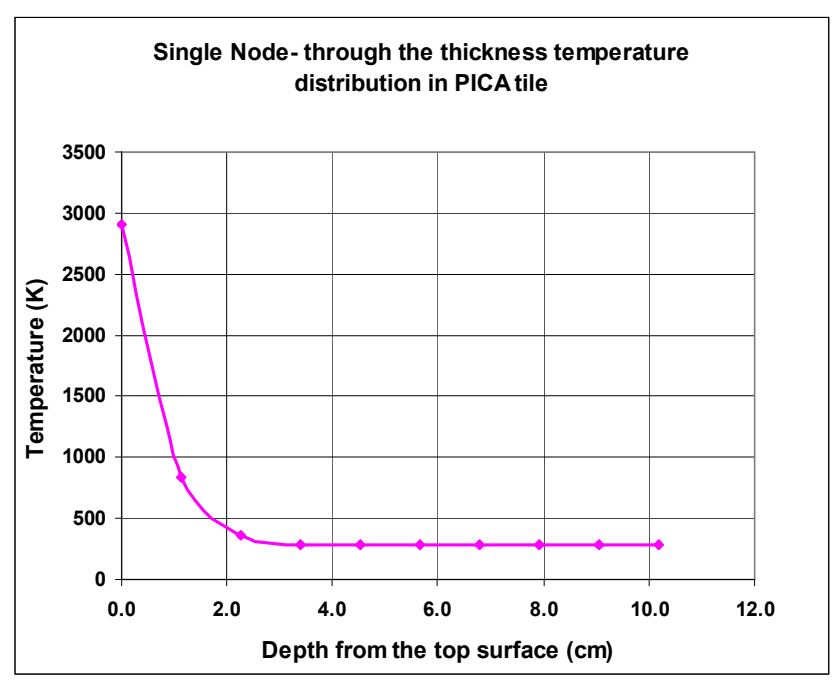

Figure 1. Temperature gradient in the thickness direction during the re-entry

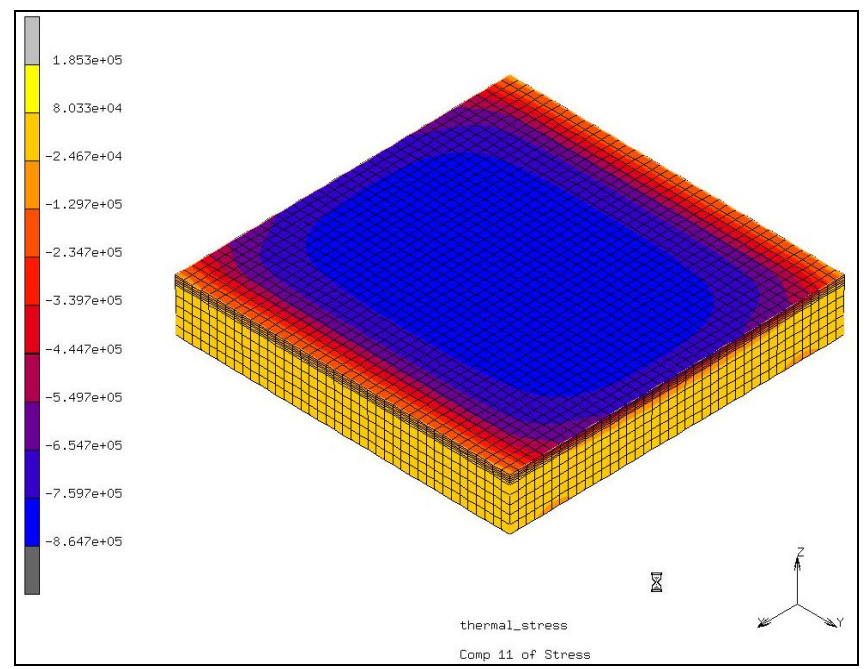

Figure 2. In-plane stress distribution in PICA tile for the temperature gradient shown in Figure 1

At present, arcjet test are performed to investigate thermal response and qualify materials for TPS. ${ }^{6}$ However, these tests are performed on very small isolated coupons, making it difficult to come to conclusions regarding failure modes in a system of bonded tile subjected to coupled thermal and mechanical loads. To address this concern, the authors have designed and conducted solar tower tests. The solar tower test facility is located at Sandia National Laboratory in Albuquerque, New Mexico. It comprises a 200-foot solar tower surrounded by a field of 211 suntracking mirror arrays called heliostats. The heliostats direct sunlight to the top of the tower where the test objects 
are affixed. The coupons are mounted to the tower on a frame and exposed to open atmospheric conditions. A radiative heat flux ranging from $10 \mathrm{~W} / \mathrm{cm}^{2}-250 \mathrm{~W} / \mathrm{cm}^{2}$ can be applied to these coupons. The dimension of the coupons range from a few centimeters to meters. In addition, mechanical loads can be applied simultaneously to the coupons with the help of load cells. This makes for very appealing circumstances to test the large arrayed PICA tiles that are representative of sizes currently being analyzed for thermal-structural response.

\section{Coupon Geometry and Test Description}

Isolated PICA tiles and arrays of multiple tiles were designed for this experiment. The isolated PICA tiles are $30.5 \mathrm{~cm}$ (12 inches) square in cross section and $5.3 \mathrm{~cm}$ (2.1 inches) thick. Each tile is mounted on a $0.32 \mathrm{~cm}(0.125$ inch) thick 6061 aluminum plate using a $0.23 \mathrm{~cm}(0.09 \mathrm{inch})$ thick layer of strain isolation pad (SIP). The SIP layer provides the required mechanical strain isolation between the tiles and the carrier structure (in this case, metal plate). Two Room Temperature Vulcanized (RTV) adhesive layers are used to bond the SIP to the tile on one side and the SIP to the aluminum plate on the other side. The RTV is a silicon-based adhesive, and the SIP layer is made of a special nylon weave. ${ }^{7}$ Figure 3 shows one of the sample coupons. These coupons are instrumented with plugs embedded with thermocouples to measure temperature profile at various depths. In addition, bondline thermocouples on each provide temperature history at the interface between the metal back plate and SIP. The depth of the embedded thermocouples is listed in Table 1 . The strain gauge locations are listed in Table 2.

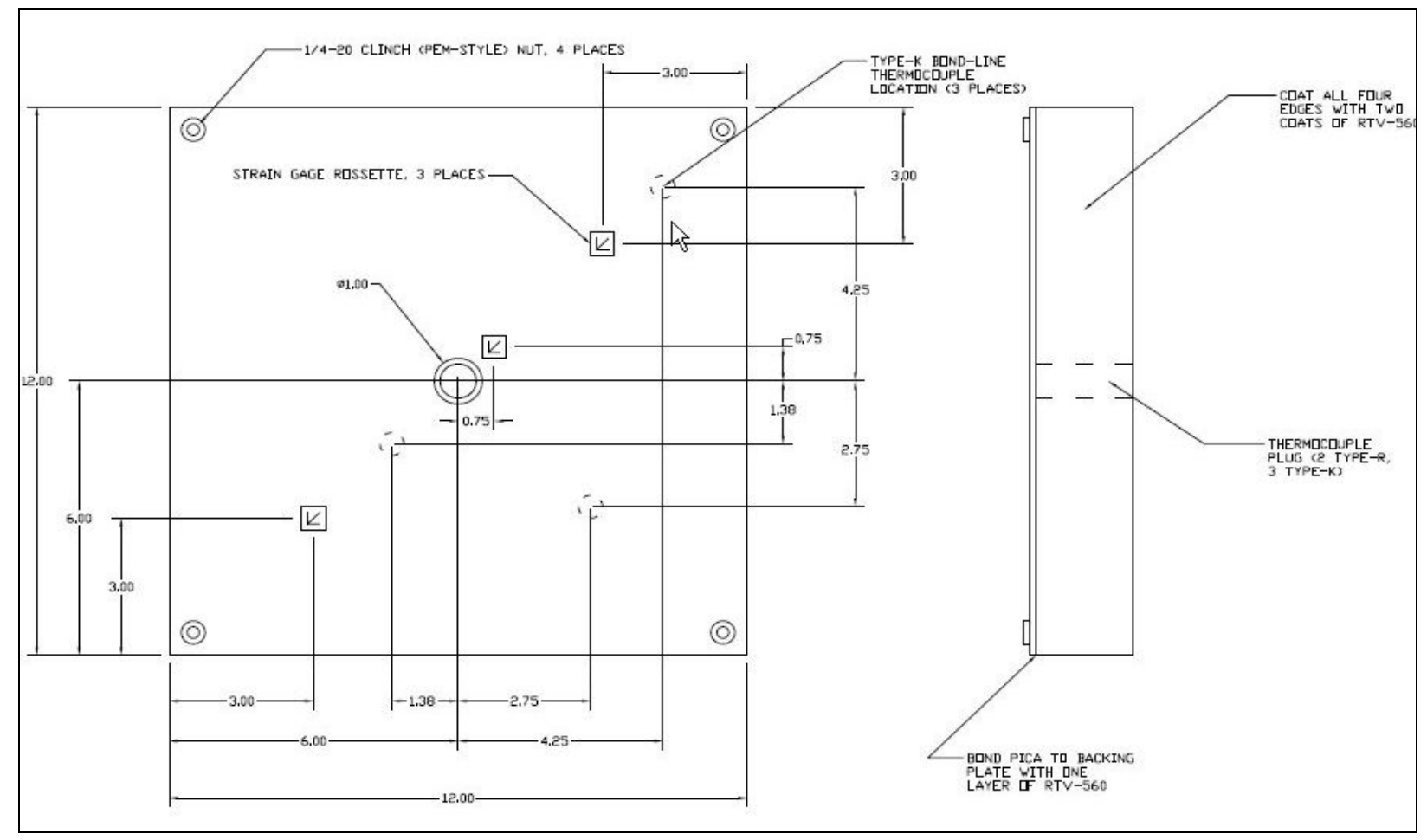

Figure 3. Drawing and Instrumentation layout of pathfinder (single tile) coupon

Table 1. Thermocouple depths for single tile (pathfinder) coupons

\begin{tabular}{|l|l|l|}
\hline Thermocouple & Depth & Location \\
\hline TC -1, Type K & $0.10^{\prime \prime}$ from surface & Center of tile \\
\hline TC -2, Type K & $0.20^{\prime \prime}$ from surface & Center of tile \\
\hline TC -3, Type K & $0.45^{\prime \prime}$ from surface & Center of tile \\
\hline TC -4, Type K & $0.70^{\prime \prime}$ from surface & Center of tile \\
\hline TC -5, Type K & Bondline & \\
\hline TC -6, Type K & Bondline & \\
\hline TC -7, Type K & Bondline & \\
\hline
\end{tabular}


Table 2. Strain gauge location for single tile coupon

\begin{tabular}{|l|l|}
\hline Strain Gauge & Location in Inches \\
\hline Sample_SG1_3C & $(\mathrm{x}=3.0, \mathrm{y}=0.0)$ \\
\hline Sample_SG2_6C & $(\mathrm{x}=0.0, \mathrm{y}=-3.0)$ \\
\hline Sample_SG3_9P & $(\mathrm{x}=-5.0, \mathrm{y}=0.0)$ \\
\hline Sample_SG4_12P & $(\mathrm{x}=0.0, \mathrm{y}=5.0)$ \\
\hline Sample_SG5_12C & $(\mathrm{x}=0.0, \mathrm{y}=3.0)$ \\
\hline Sample_SG6_9C & $(\mathrm{x}=-3.0, \mathrm{y}=0.0)$ \\
\hline
\end{tabular}

In order to verify the magnitude of thermal stresses developed due to steep temperature gradients, we needed to mount strain gauges on the coupons. However, as PICA is a very porous material, it was difficult to mount a strain gauge and obtain meaningful information. Therefore, the authors decided to mount the strain gauges on the metal back plate and compare the results with finite element predictions. Optical pyrometers are used to record the surface temperature. These coupons are used in the feasibility study.

The multiple tile coupons are fabricated with eight PICA tiles and several LI-2200 tiles as shown in Fig. 4. Four of the PICA tiles are $25.4 \mathrm{~cm}$ (10 inches) square, cross section, and $6.3 \mathrm{~cm}(2.5$ inches $)$ thick. These are representative of the tile sizes that are currently being considered for the Orion heatshield. The other four are designed as partial tiles with $25.4 \times 9.7 \mathrm{~cm}(10 \times 3.8$ inch), cross section. The PICA tiles are surrounded by narrow LI-2200 tiles to prevent heat conduction from the sidewall. One $9.7 \mathrm{~cm}(3.8$ inch) square LI-2200 tile with RCG coating was installed along with PICA tiles to measure surface temperature. Figure 4 shows the layout of these tiles. All of them are $6.3 \mathrm{~cm}$ (2.5 inches) thick and are bonded with $0.23 \mathrm{~cm}(0.09$ inch $)$ thick SIP-RTV system to a $0.32 \mathrm{~cm}(0.125 \mathrm{inch})$ thick $6061 \mathrm{Al}$-metal plate. For this system, the SIP was set back by $1.3 \mathrm{~cm}(0.5 \mathrm{inch})$, as is the current practice for shuttle tiles. Filler bar material was used in the space between the set-back SIP. The gap between the tiles is filled with gap filler material. Gap fillers serve the critical role of keeping the tiles integrated to the system. At present, TPS ADP is investigating various gap-filler options. It is important to investigate how the tiles, gap fillers, and the system as a whole perform in the presence of coupled thermal-mechanical loading. Therefore, three tiled array coupons with three different types of gap filler material were fabricated. The following gap filler options are used for these tiles:

- Solid silicone rubber (shore 70) — fully bonded on both sides

- RTV with silicone sponge gap filler

- PICA on edge (bonded to the side walls of the tiles on either side with RTV-560)

Some of the tiles in this multi-array are instrumented with thermocouple plugs, as shown in Fig. 4. The depth of these thermocouples is listed in Table 3. There are three bondline thermocouples to measure the interface temperatures. Strain gauges are used at the metal plate facing the SIP layer to record strain measurements. The nominal location for these strain gauges is listed in Table 4 . 


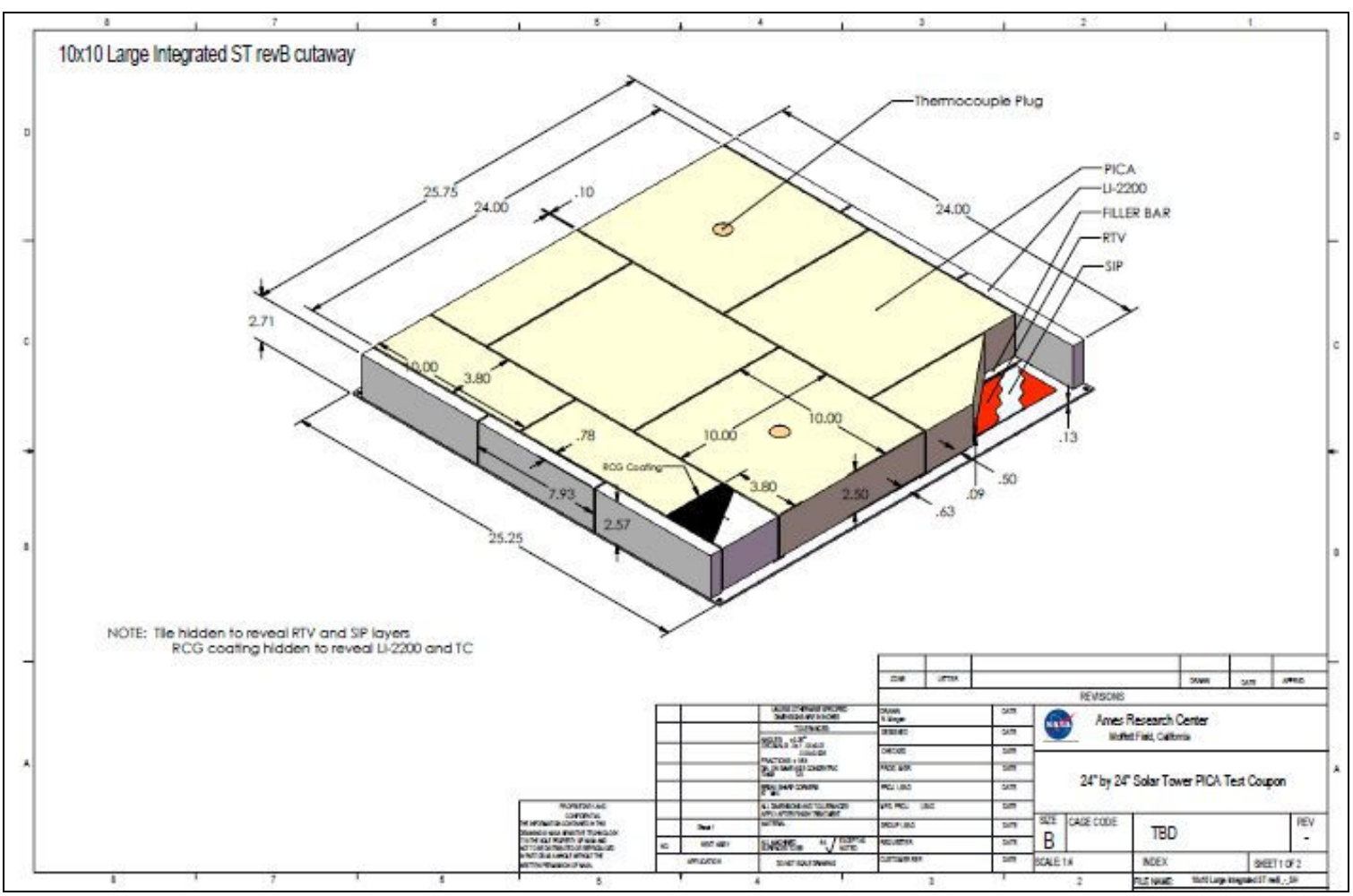

Figure 4. Drawing and instrumentation of multi-tile array coupon

Table 3. Thermocouple depths and locations for multi-tile array

\begin{tabular}{|l|l|l|}
\hline Thermocouple & Depth & Location \\
\hline TC-1, Type R & $0.15^{\prime \prime}$ from surface & Center of tiles 1 \& 6 \\
\hline TC-2, Type R & $0.30^{\prime \prime}$ from surface & Center of tiles 1 \& 6 \\
\hline TC-3, Type K & $0.45^{\prime \prime}$ from surface & Center of tiles 1 \& 6 \\
\hline TC-4, Type K & $0.60 "$ from surface & Center of tiles 1 \& 6 \\
\hline TC-5, Type K & $1.20^{\prime \prime}$ from surface & Center of tiles 1 \& 6 \\
\hline TC-6, 7 and 8 Type K & Bondline & \\
\hline TC-9, Type R & Surface & LI-2200 tile \\
\hline
\end{tabular}

Table 4. Strain gauge location on multi-tile array

\begin{tabular}{|c|c|c|c|c|c|c|}
\hline $\begin{array}{l}\text { Y Direction } \\
\text { Measurement } \\
\text { Strain Gauge }\end{array}$ & & & & $\begin{array}{l}\text { X Direction } \\
\text { Measurement } \\
\text { Strain Gauge }\end{array}$ & & \\
\hline Gauge & $\mathrm{X}$ & $\mathrm{Y}$ & $\begin{array}{l}\text { Reason for both } \\
\mathrm{X} \text { and Y } \\
\text { direction gauge } \\
\text { placement }\end{array}$ & Gauge & $\mathrm{X}$ & $\mathrm{Y}$ \\
\hline & (inches) & (inches) & & & (inches) & (inches) \\
\hline 1 & 13.025 & 7.275 & $\begin{array}{l}\text { Measure strain } \\
\text { away from gap } \\
\text { fillers and loads }\end{array}$ & 1 & 13.025 & 11.775 \\
\hline
\end{tabular}




\begin{tabular}{|l|l|l|l|l|l|l|}
\hline 2 & 6.025 & 7.275 & $\begin{array}{l}\text { Measure strains } \\
\text { close to } \\
\text { mechanical } \\
\text { loads }\end{array}$ & 2 & 6.025 & 11.775 \\
\hline 3 & 10.625 & 20.875 & $\begin{array}{l}\text { Measure right } \\
\text { below the } \\
\text { location } \\
\text { corresponding to } \\
\text { gap filler }\end{array}$ & 3 & 13.025 & 14.775 \\
\hline 4 & 22.625 & 14.275 & $\begin{array}{l}\text { Measure right } \\
\text { below PICA tile } \\
\text { close to gap } \\
\text { filler }\end{array}$ & 4 & 20.625 & 14.275 \\
\hline 5 & 19.225 & 18.375 & $\begin{array}{l}\text { Measure strains } \\
\text { close to } \\
\text { mechanical } \\
\text { loads }\end{array}$ & 5 & 19.225 & 22.875 \\
\hline
\end{tabular}

\section{Analytical Model Development}

The thermal-mechanical finite element analyses are performed with the MSC.Marc commercial finite element package. ${ }^{8}$ MSC.Marc supports fully transient, non-linear, coupled thermal/mechanical FE analyses. MSC.Marc can also handle non-linear and temperature-dependent material properties. MSC.Marc includes an integrated user interface, Mentat, for pre- and post-processing. The package allows the application of a wide range of thermal and mechanical boundary conditions, such as applied heat flux and convective heating, surface radiation, and applied force loads and deflections. The boundary conditions can be simple constant values, or they can vary both spatially and temporally.

The single tile model is constructed of a mesh of 8-noded hexahedral (brick) elements with linear interpolation functions. The tile elements are $1.27 \mathrm{~cm}(0.5 \mathrm{inch})$, except the top is created with finer mesh to accommodate the steep thermal gradient. The material properties are taken from the ADP material property data file that includes the recently measured thermal and mechanical properties of PICA. The SIP and RTV layer is constructed using a single row of elements with the material properties of RTV-impregnated SIP layers. The metal backplate was also modeled using a single row of hexahedral elements.

The multi-tile array model is constructed using 8-noded brick elements for PICA and LI-2200 tiles and 20-noded brick elements for the gap filler. Each tile, gap filler, and the metal carrier structure are modeled as a separate elastic contact body. The top view of the FEM model showing the different contact bodies is shown in Fig. 5. The mechanical displacements are applied to the metal frame along two lines parallel to the $\mathrm{x}$-axis. The temperature gradient across the thickness was applied as a state variable boundary condition.

PICA and SIP_RTV combination materials are modeled as 3-dimensional orthotropic materials. Material ablation or pyrolysis was not considered. Based on the material test studies, it was assumed that PICA displays virgin material properties until $288{ }^{\circ} \mathrm{C}\left(550{ }^{\circ} \mathrm{F}\right)$ and fully pyrolizes to carbon char at $760{ }^{\circ} \mathrm{C}(1400 \mathrm{~F})$. Therefore, for temperatures above $760{ }^{\circ} \mathrm{C}(1400 \mathrm{~F})$ char, thermal and mechanical properties are used. For temperatures that are inbetween the above mentioned values, a linear interpolation was used between the virgin and charred PICA properties. 


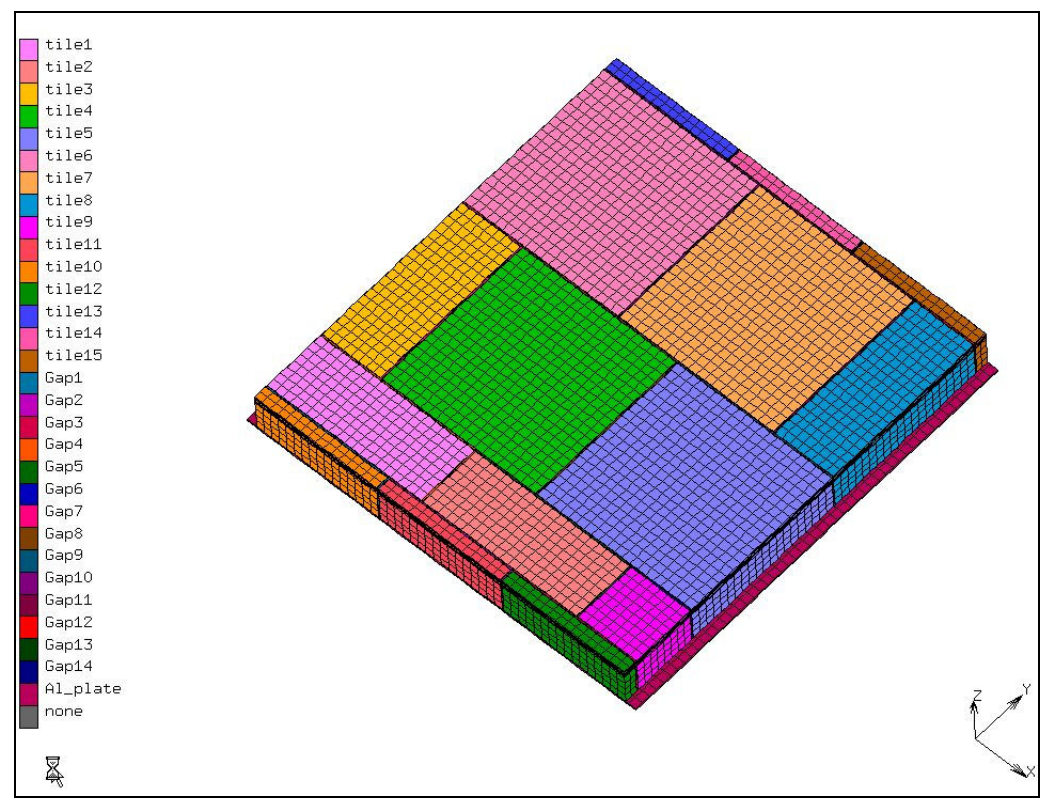

\section{Figure 5. Finite Element mesh showing the different contact bodies for multi-tile array model}

\section{Results}

The first test series, with single PICA tiles (pathfinder coupons), was carried out in June 2008 at Sandia. It was demonstrated that, with help of gaseous $\mathrm{N}_{2}$ flow, PICA tiles could be heated by a focused solar heat flux without burning in atmosphere. Radiative-flux of $150 \mathrm{~W} / \mathrm{cm}^{2}$ was applied to these coupons for a duration of 120 seconds. Magnitude and duration were decided based on finite element analysis. (A detailed description of this analysis is provided in subsequent sections.) The top two thermocouples in the plug on these coupons were burned during the test, and the authors were not able to obtain the temperature distribution after 40 seconds of the start of test. However, the other two in-depth thermocouples and the bondline thermocouples were used to provide temperature history for comparison with finite element models.

For single-tile models, the metal plate was constrained at four corners in all three dimensions. Thermal loads were applied first in the form of face heat flux for the pre-test analysis. Coupled thermal-mechanical analysis was conducted to optimize the amplitude and duration of the heat flux. Figure 6 shows the temperature profiles predicted for $150 \mathrm{~W} / \mathrm{cm}^{2}$ heat flux. The highest temperature is $2000 \mathrm{~K}$. It shows a steep temperature gradient through the thickness. Figure 7 shows the corresponding in-plane $\sigma_{\mathrm{xx}}$ stress distribution due to thermal gradient generated by 150 $\mathrm{W} / \mathrm{cm}^{2}$ heat flux. The in-plane compressive stresses were in the range of $-0.8 \mathrm{MPa}(-116 \mathrm{psi})$, which is below the allowable limit of $-0.87 \mathrm{MPa}$ (127 psi) for virgin PICA and $-1.793 \mathrm{MPa}$ (260 psi) for char PICA. To compare the strain-gauge data obtained from these tests, the temperature distribution obtained from thermocouples was applied to the model, and predicted strain was compared against the strain-gauge values. Figure 8 shows this comparison for one of the coupons. The magnitude of the predicted stress matched well with the test values. As predicted by analysis, there was no catastrophic failure seen during the test. The authors did see small surface cracks in the through-the-thickness direction in the char layer on one of the coupons during the X-ray analysis that did not have a thermocouple plug on it. The current hypothesis is that these types of surface cracks occur during the cooldown period. In the next test series, a rampdown (as opposed to step) cooling will be used. If cracks reappear, then further tests will be planned with dual heat pulses to investigate the impact of these surface cracks on the reliability of the heatshield. Thermal-structural analysis for these heat flux cycles will be conducted simultaneously, to predict the stress distribution. 
Extended abstract for the 41st AIAA Thermophysics Conference, San Antonio, Texas, 22-25 June 2009

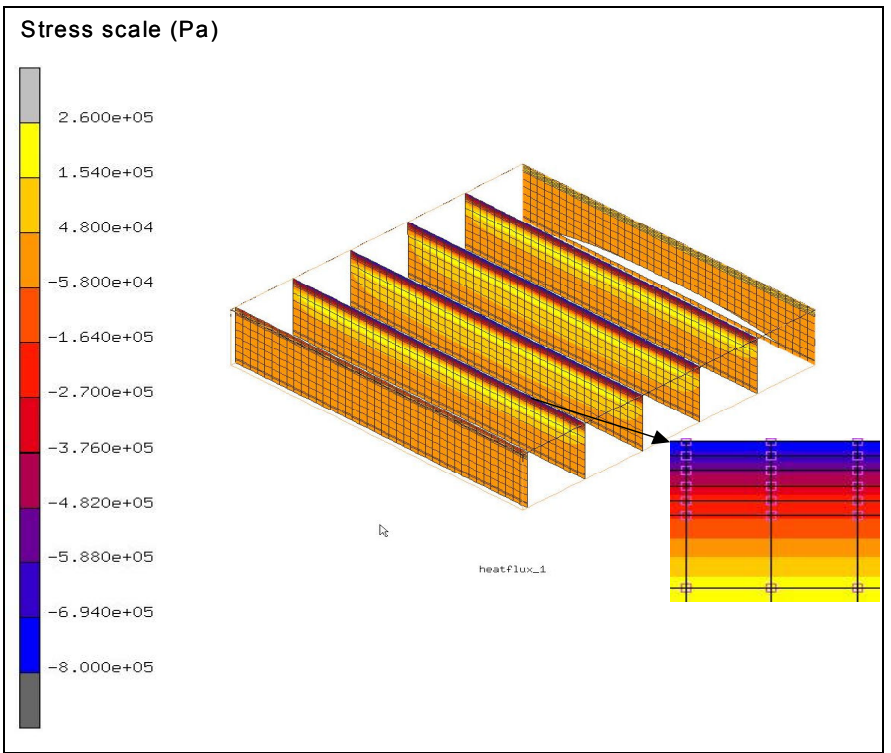

Figure 6. Temperature gradient for $150 \mathrm{~W} / \mathrm{cm}^{2}$ heat-flux applied to PICA tile

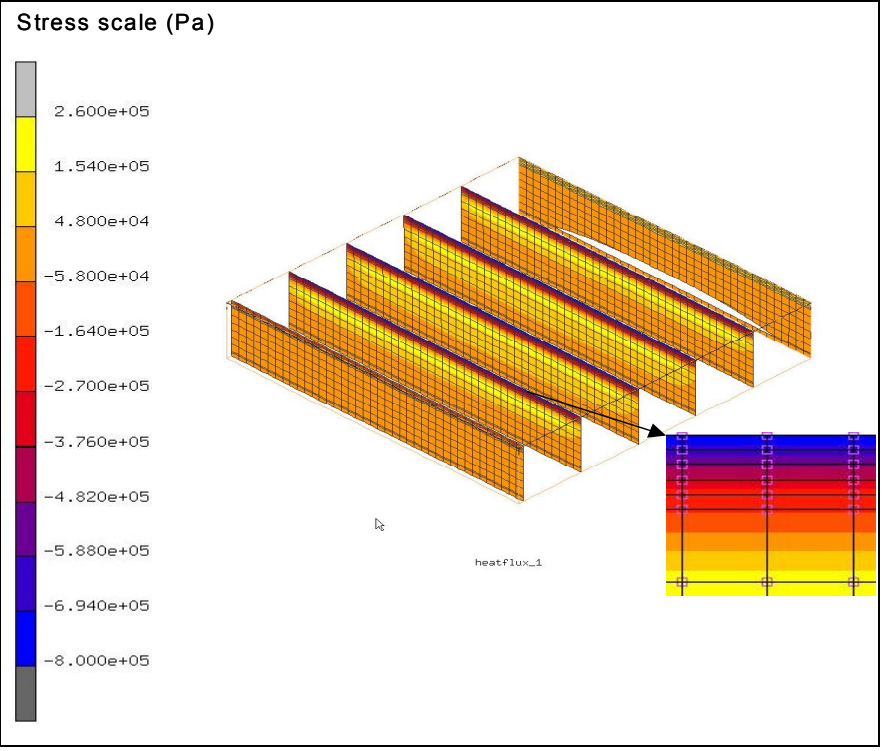

Figure 7. In-plane stress distribution in PICA tile for the temperature gradient shown in Figure 6 


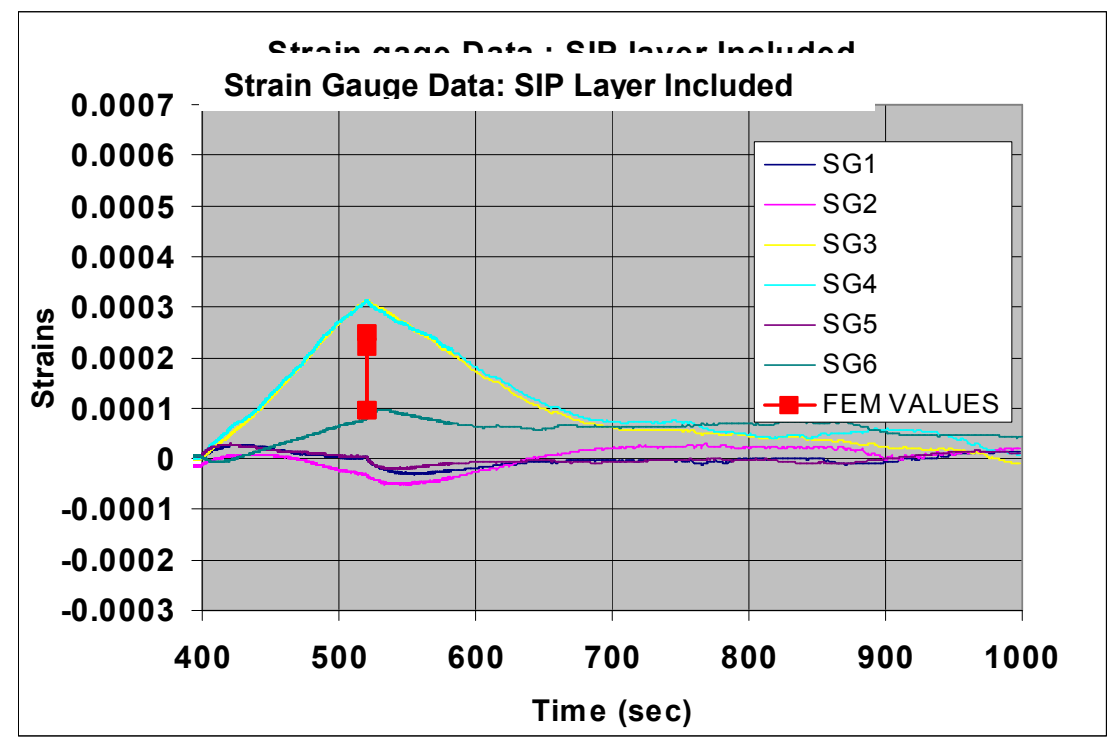

\section{Figure 8. Strain data obtained on Pathfinder coupons during the test and comparison with FEM values during the peak change in flux.}

Preliminary analysis is being performed for the multi-tile array system. Figures 9 (a) and 9(b) show the in-plane stress distribution for thermal-only and coupled thermal-mechanical load cases for PICA tiles bonded on both sides with RTV gap-filler material. The prime objective for these preliminary analyses is to recommend suitable loads for the arrayed coupons in order to achieve higher-than-allowable stress levels in the presence of coupled thermalmechanical loads and to observe the failure modes. The second series of solar tower experiments that includes the testing of multi-tile array system is scheduled for second week of November 2008. In the final paper, we plan to include the second series test results and post-test analysis for validation of model predictions.

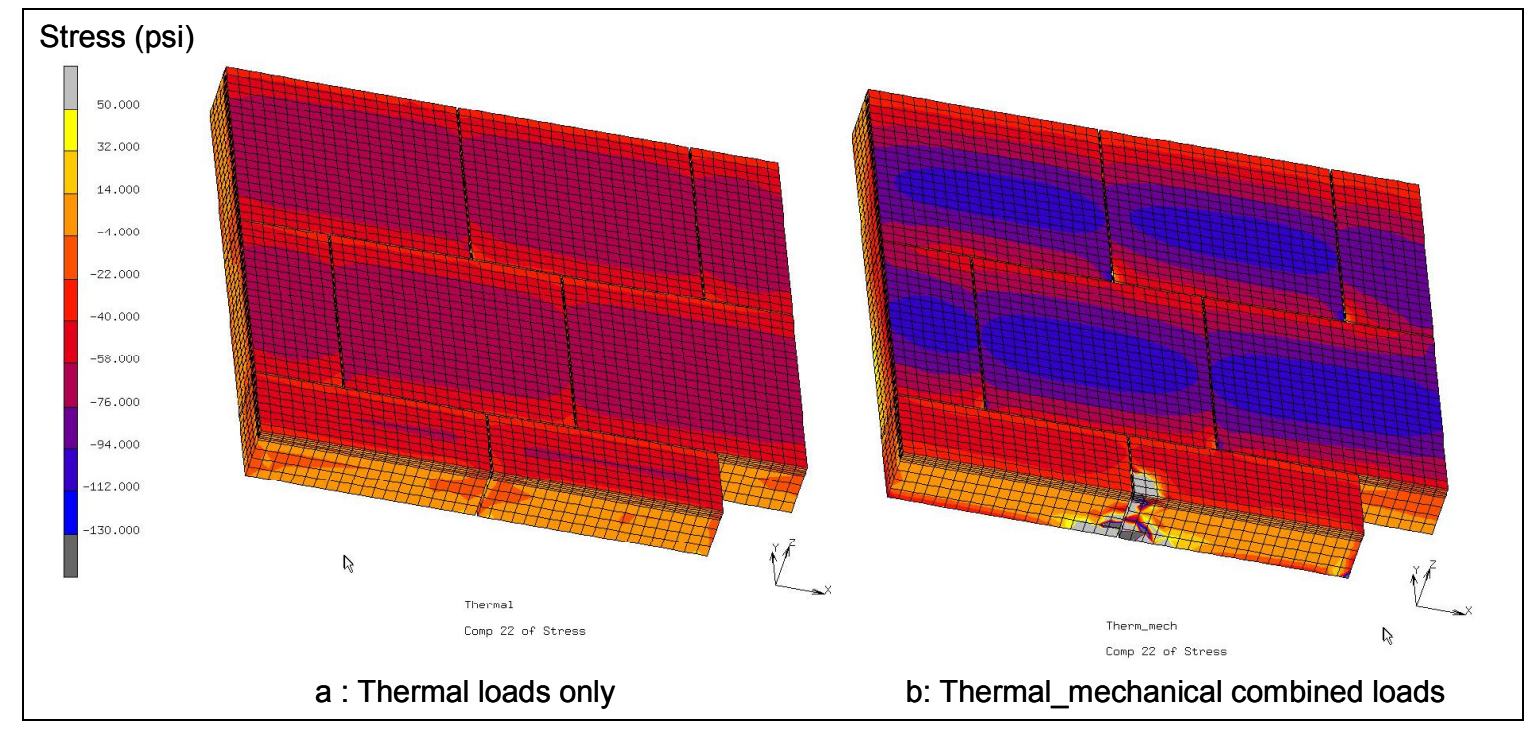

Figure 9. (a) and (b). In plane stress $\sigma_{y y}$ distribution in PICA tiles

\section{Conclusions}

The authors were able to design and analyze the pathfinder coupons for first test series for feasibility studies. Analyses for these coupons predicted stress levels below the allowable limits for virgin as well as char PICA. The 
test data was in agreement with the model prediction and no catastrophic failure was observed during the test. One of the coupons did show the presence of small surface cracks in the char layer. Further tests are being performed to address whether this occurred due to an instant cooling followed by high heat flux, and a ramp cooling cycle will eliminate this cause. Authors are also analyzing multi-tile system and in-depth analyses as well as experiments that will be conducted in the subsequent weeks and reported in the final paper.

\section{Acknowledgment}

The authors gratefully acknowledge the support provided by the Orion TPS Advanced Development Project and NASA Ames Research Center through contract to the ELORET Corporation.

\section{References}

${ }^{1}$ Tran, H., Johnson, C, Rasky, D., Hui, F., Chen, Y.-K., and Hsu, M., "Phenolic Impregnated Carbon Ablators (PICA) for Discovery Class Missions," AIAA Paper 96-1911, June 1996.

${ }^{2}$ Willcockson, W.H. "Stardust Sample Return Capsule Design Experience,” Journal of Spacecraft and Rockets, Vol. 36, No. 3, 1999, pp. 470-474.

${ }^{3}$ Chen, Y.-K., and Milos, F.S., "Multi-Dimensional Effects on Heatshield Thermal Response for the Orion Crew Module," AIAA Paper 2007-4397, AIAA Thermophysics Conference, June 2007.

${ }^{4}$ Lockwood, M.K., "Introduction: Mars Science Laboratory: The next generation of Mars Landers," Journal of Spacecraft and Rockets, Vol. 43, No. 2, 2006, pp. 257.

${ }^{5}$ Milos, F.S. and Chen, Y.-K., "Two-Dimensional Ablation, Thermal Response, and Sizing Program for Pyrolyzing Ablators," AIAA Paper 2008-1223, AIAA Aerospace Sciences Meeting and Exhibition, January 2008.

${ }^{6}$ Covington M. A., Heinemann J.M., Goldstein H. E., Chen, Y.-K., Terrazas-Salinas I., Balboni J.A., Olejniczak J. and Martinez E.R., "Performance of a Low Density Ablative Heat Shield Material," AIAA Paper 2004-2273, AIAA Thermophysics Conference, July 2004.

${ }^{7}$ Anon., "NASA-Space Shuttle Manual 1988," pp.169.

${ }^{8}$ Anon., "MSC.Marc User Guide Version 2007". 